\title{
Sprawling Biopolis jazzes up Singapore's science scene
}

The first phase of Biopolis, Singapore’s US $\$ 288$ million complex of research laboratories, opened on 29 October to the strains of a jazz quintet led by Edison Liu, executive director of the Genome Institute of Singapore. Designed to house more than 2,000 researchers in 2 million square feet, Biopolis is a concrete and glass demonstration of the Singapore government's determination to establish the city-state as the premier biosciences center in Asia.

"Biopolis was conceived as the cornerstone of a much broader vision to build up the biomedical sciences industry in Singapore," Deputy Prime Minister Tony Tan said at the opening. A second phase with as many as 5,000 scientists is planned, but the timing has not yet been announced. Biopolis will eventually become a feature in a 500-acre arts and sciences 'theme park', complete with shops and homes.

The biomedical sciences sector contributed $\$ 5.6$ billion in manufacturing output and $\$ 3.7$ billion in value added to the economy in 2002 , barely three years into the program. Although overshadowed by hundreds of billions of dollars in investments, the numbers are reminiscent of the lead-up to Singapore's becoming a microchip powerhouse in the 1990s.

Biopolis' network of spacious institutes and laboratories was designed to be a magnet for biomedical and allied scientific talent from around the world. A key ingredient in its attraction is the juxtaposition of dozens of industry, government and academic research facilities.

Its approach may well be successful. Following the opening, the Singapore government announced it would create a Center for Molecular Medicine to focus on translational

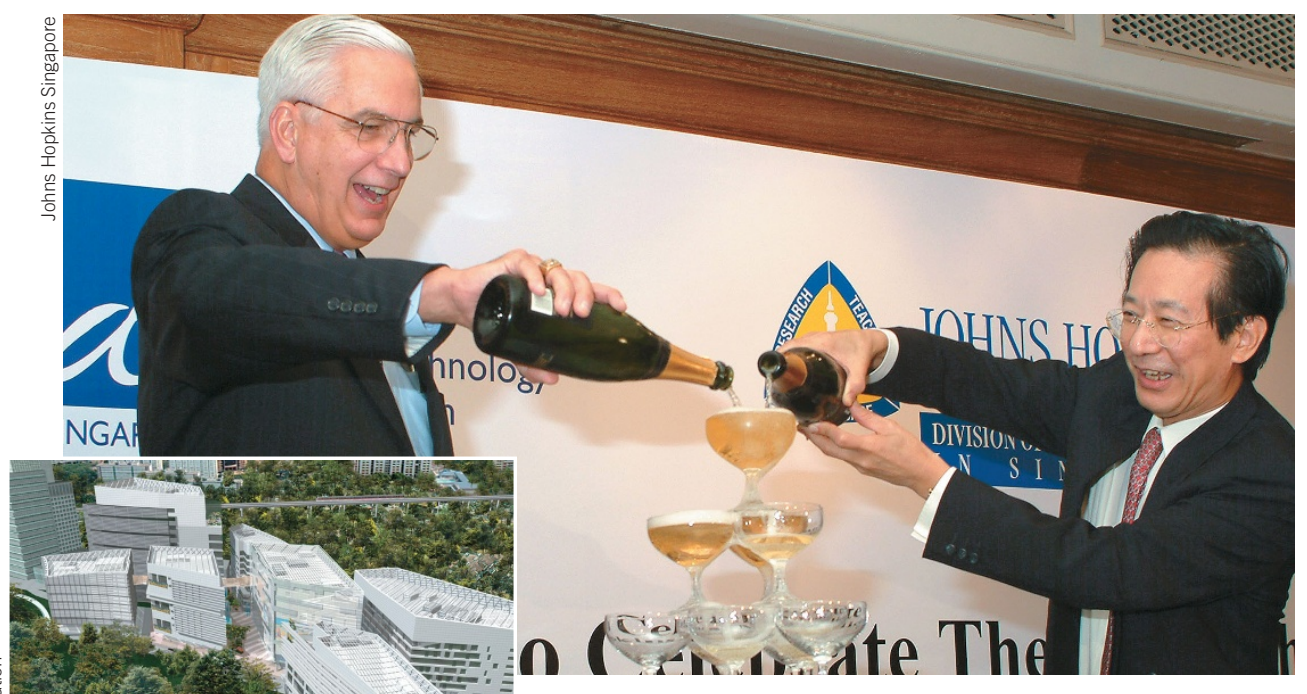

Singapore it on: Champagne and money flowed at the opening last week of Biopolis (inset).

research. On 28 October, Johns Hopkins University also announced a new division of its School of Medicine that would be entirely located at Biopolis, its first location outside Baltimore. "Space constraints alone mean that we can't grow at our Baltimore campus," says Edward D. Miller, CEO of Johns Hopkins Medicine. The new division will be fully engaged in research, and is expected to draw promising students and postdocs from around the world. Miller says the division will focus on diagnostic and therapeutic immunology.

Hopkins has had a research program in Singapore for the past five years, and this agreement extends it for at least five more. The new division will recruit up to 12 full-time faculty members, Miller says.

Funding for the division comes from a grant from Singapore's Ministry of Trade and Industry. Details have not been revealed, pending final approval, but the grant is expected to be around \$28.8 million. Officials have been tightlipped about other sources of funding, but a significant proportion is expected to come from the US National Institutes of Health.

The Genome Institute of Singapore and the Bioinformatics Institute moved into Biopolis in September, and Johns Hopkins is expected to join them in early 2004.

Michael Frith, Singapore

\section{European Parliament set to ban cloning for transplantation}

Just two days before the United Nations deferred for two years its vote to ban human cloning, the European Parliament moved to enact just such a ban in the European Union (EU).

On 4 November, the Committee on the Environment, Public Health and Consumer Policy of the European Parliament accepted an amendment prohibiting the use of cloned human cells for medical transplants. The ban would be part of a new directive setting safety and quality standards for donation, testing and storage of all types of human tissues and cells, and possibly the manufacturing and distribution of industrial products based on them.

Whether the ban will become law is uncertain, however, because the European Commission and the Council of Ministers, in which all member states have veto rights, already rejected the idea last April. Safety regulations, they said then, cannot be used to impose moral rules on member states-especially when the states disagree. Countries such as Germany and Italy forbid any form of human cloning, but others, such as Sweden and the UK, allow cloning of patient cells into embryos for transplant purposes.

The committee, in a thinly veiled attempt to bypass this objection, now says cloning is too 'risky'. Citing evidence of molecular and cellular defects in Dolly and her successors, the amendment proposes a ban on the use of cloned human embryos and human-animal hybrids as sources of transplant material. The ban would not apply to nonclinical research.
The squabbling EU bodies have until 15 December-or at the very latest, early next spring - to find common ground. If they don't agree, all safety rules, not just the cloning ban, are off the table, possibly for many years.

Meanwhile, after two years of discussion, the United Nations on 6 November voted $80-79$ to postpone voting on a global ban on human cloning. The US and 44 other countries had signed on to a ban on both reproductive and therapeutic cloning; 14 others, led by Belgium, would leave the choice to individual countries.

To avert a showdown, a bloc of Islamic countries led by Iran offered the deferment. The delay permits more research, backers said, perhaps making it easier to reach a consensus in 2005.

Peter Vermij, Washington, DC 